\title{
Multi Criteria Evaluation for Vocational School Zone Based on Geographic Information System
}

\author{
I Widianingsih $^{1}$, I M Purwaamijaya ${ }^{2}, \mathrm{R} \mathrm{M} \mathrm{Masri}^{3}$ \\ \{irmaw@upi.edu ${ }^{1}$, ais_imp@upi.edu ${ }^{2}$, ,rinamasri@upi.edu ${ }^{3}$ \} \\ Civil Engineering Department, Universitas Pendidikan Indonesia ${ }^{1,2,3}$
}

\begin{abstract}
The objectives of research were (1) to design conceptual model and to build multi-criteria evaluation for vocational school zone based on geographic information system (GIS), (2) creating database management system of vocational school zone based on GIS, (3) producing thematic map of vocational school zone based on GIS. The research is using descriptive method. The research population is physical, chemical, biological and environmental conditions. The sampling technique is purposive. Research instruments are measurement and mapping tools, questionnaires, observations, computer hardware and software. Primary data were taken by physical, chemical and biological environments. Secondary data taken are maps of soil texture, soil drainage, soil type, erosion, slope, the effective depth of soil and flooding. Spatial analysis is used to superimpose layers, using GIS software.
\end{abstract}

Keywords: Geographic information system, Multi-criteria decision making, spatial analysis

\section{Introduction}

Complex criteria that integrate multiple stakeholder perspectives should ideally be included in the land-use suitability map. Land suitability maps for housing are used to illustrate the feasibility of sustainable development approaches and economic competitiveness. Assessment of the criteria requested to determine land suitability for housing using Geographical Information System technology. The initial steps of the procedure are described as an evaluation of the noise level. ELECTRE-TRI is a multi-criteria outracing analysis method used in the study because the required criteria are heterogeneous and are measured at various scales. Computational limitations make evaluating the suitability of each point in an area impractical. Evaluate the relationship of closeness and classification of research areas into homogeneous zones using mathematical functions. Conformance index assessment uses functions that are compatible with the outranking function. Efficient negotiations and uses for handling conflicts inherent in land use planning are supported by the maps produced. [1].

Specific deterministic analysis in key application fields such as spatial search limit the functionality of GIS. The availability of means to evaluate various alternatives based on several criteria and conflicting objectives for users is the reason for the integration of multicriteria evaluation techniques (MCE) continues. Search for sites suitable for the disposal of radioactive waste in the UK using Arc / GIS info is presented as an example application [2].

The explosion at the landfill at the old location occurred in 2005 so a new landfill site is needed. The explosion at the landfill at the old location occurred in 2005 so a new landfill site 
is needed. All requirements have been met by the new landfill and the surrounding community is not difficult to accept. An example of determining the location of a new landfill site using GIS and decision-making procedures was discussed in the study. It is discussed in the study. Case studies are given special term names, namely: Single Objective Multiple Criteria. Problem identification, determination of objectives and criteria, standardization of criteria, determination of weights, combining criteria, and analyzing the results through sensitivity analysis are the steps of the GIS-DM procedure. The determination of the location of waste disposal is sensitive to the weight criteria and preferences of decision-makers, as well as the area. [3]. Various alternatives must often be chosen by natural resource management. Instruments for making rational decisions, especially a combinations between GIS, multi evaluation criteria (MCE) and analytic hierarchy processes (AHP) [4]. Determination of suitable forest harvest zones in tropical forests is the purpose of the study. The data was prepared spatially in GIS and the analysis was carried out systematically by the evaluation method which is the integration capability of GIS and decision support systems, demonstrated in the implementation of the AHP method for MCE.

Determination of alignment steps is the most important step in highway planning activities. Road alignment determines the majority of the costs of construction, repair and maintenance of the road and the performance of its operations and social-environmental impacts. Multi-criteria decision making (MCDM) and GIS are combined with a 3-stage model in the study and developed for the process of determining highway alignment. Standardize the criteria map using the Fuzzy function. Determination of weight criteria using AHP. The combination of criteria maps uses the Linked Weighted combination method. The road project in the field tests the model developed. Internet case study for applying models using IDRISI software. Taking the evaluation constraints, making alternative leveling with different points of view and making choices between alternatives with different points of view becomes easy in the process of making it. [5]. Substantial evidence of social gradients in various health outcomes has been produced by researchers over the past few decades about the increase in systematic differences in income, education, working conditions, and family dynamics in the population. Social gradients in health are measured using a deficit index, which is usually built from socio-economic aggregate data taken from the national census - a technique that began at least until the 1970s. The use of geographic information science (GIS) to build indexes was proposed by researchers in the study [6].

Anthropogenic and natural features on the earth's surface area affected by landslides which are geomorphological phenomena. Several factors that contribute to landslides have been identified by many previous studies. Physical characteristics such as the slope, aspects, and land cover of the earth's surface are factors that contribute to landslides [7]. Landslide vulnerability maps using the best-worst methodology (MCDA-BWM) multi-criteria spatial decision analysis (GCD) is the goal produced in the study. National landslide database, aerial photographs, and also by conducting field surveys compiling landslide maps. Fifteen conditioning factors relevant to mapping landslide susceptibility, altitude, slope, aspect, distance to road network, distance to river, distance to error, lithology, normalized vegetation index difference (NVDI), wet topographic index (TWI), stream power index (SPI), sediment transport (STI), annual rainfall, distance to urban areas, and land use/cover are considered in the methodology for obtaining 1082 landslide locations. The nature and severity of the criteria are observed and tested using two scenarios, different aggregations of BWM methods are considered by expert evaluations. The receiver operating characteristic (ROC) checks the predicted performance of the resulting map. The area under the ROC curve for the weighted linear combination (WLC) and the ordered weighted average (OWA) MCDA-BWM 
aggregation method has very high accuracy confirmed by the validation results. The adoption of the best-worst method proposed is the first step in the development of landslide risk management and they are expected to be used by local governments for effective management planning to obtain results from landslide vulnerability assessments. [8, 9, 10, 11, 12].

\section{Methods}

The multi-criteria decision model (MCDM) using the analytical hierarchy process (AHP) method was used for collecting terrestrial data, the spatial analysis using GIS method was used for presenting thematic zone system. The AHP algorithm is a guideline for the conceptual and functional model and a geographical information system is an instrument for the implementation phase.

The analytical hierarchy process method goes through stages, namely: (1) Build a hierarchy. The hierarchy is built into several related levels, namely: the level of global objectives, the level of special objectives, the level of attributes and alternative levels of problem-solving, (2) Compares the decision element based on a partner and reduces the concept of decision making, (3) The parameters are defined by normalizing the eigenvector associated with the maximum eigen in the ratio matrix, (4) Calculation of the weight of each parameter is calculated using the pair comparison method with the assumption that if the CR value $<0.10$, it shows a good level of consistency or sensitivity, meaning that the weight obtained is quite rational. However, if the weight is $>0.10$, an inconsistent assessment has occurred or the sensitivity value is poor, meaning that the MCDM calculation must be repeated before proceeding to the spatial analysis, (5) Spatial analysis is the aggregation of relative weights that have been produced in the previous stage to produce composite weights as the final score in spatial decision making.

The geographic information system method go through stages, namely: (1) creating conceptual model using matrix which presenting linkages between the resulting feature, users and resolution, (2) structuring functional model using matrix which presenting the relationship between resulting feature and graphical information entity, (3) collecting data which is consisting of graphical and attribute data,(4) data categorization based on the type and level of accuracy of the data, (5) digitizing base map refers to the conceptual and functional models, (6) entering attribute data with data structures refers to the conceptual and functional models, (7) operating spatial analysis of several thematic layers with arithmetic operations, namely boundary intersection, union, inverse, area, perimeter, abscissa center, ordinate center, etc, (8) programming to build systems of interaction with users, (9) trials to stakeholders, (10) revision, (11) implementation.

\section{Result and Discussion}

\subsection{Multi Criteria Decision Model (Analytical Hierarchy Process)}

Parameter weights are obtained from 2 experts as can be seen in Table 1, to get the value of parameter weights the average weight of each value of the experts is calculated. The results of the average calculation of the parameter weights from 2 experts indicate the average value of drainage weights is greater than the average value of the other parameter weights. This 
shows that drainage is more influential by $22 \%$ on the evaluation of land capability. The average weight value of rainfall is 0.19 or $19 \%$, its effect on the analysis of land capability. The average weight value for effective soil depth is 0.15 or $15 \%$ of the effect. The average weighted flood value is 0.12 or $12 \%$ of its influence in evaluating land capability. The average weight value of soil texture is 0.11 or $11 \%$ of its effect on the evaluation of land capability. The value of erosion sensitivity is 0.09 or $9 \%$. The average weight value of rocks is 0.07 or only $7 \%$ and the average weight value of the slope is only 0.05 or $5 \%$.

Table 1. Use eai table caption and text.

\begin{tabular}{llccc}
\hline \hline \multirow{2}{*}{ No Parameter } & & Weight & Average \\
\cline { 3 - 4 } & & Expert 1 & Expert 2 & \\
\hline 1. & Drainage & 0.23 & 0.21 & 0.22 \\
2. & Rain fall & 0.18 & 0.20 & 0.19 \\
3. & Soil effective depth & 0.15 & 0.15 & 0.15 \\
4. & Flood & 0.13 & 0.10 & 0.12 \\
5. & Soil texture & 0.11 & 0.12 & 0.11 \\
6. & Erosion & 0.10 & 0.08 & 0.09 \\
7. & Rock & 0.07 & 0.07 & 0.07 \\
8 & Slone & 0.05 & 0.06 & 0.05 \\
\hline \hline
\end{tabular}

\subsection{Thematic Map for Vocational School Zone}

Thematic map of drainage as can be seen in Figure 1.a contains 4 layers, that are (1) well drainage 423. $26 \mathrm{~km}^{2}(24.02 \%)$, (2) good drainage $130.41 \mathrm{~km}^{2}(7.40 \%)$, (3) rather bad 616.46 $\mathrm{km}^{2}(34.98 \%)$, and (4) bad $592.28 \mathrm{~km}^{2}(33.61 \%) .48$ zone UTM coordinates tied all layers. Affine method which transformed satellite imagery screen shoot to UTM was used for coordinate transformation.

Thematic map of rain fall as can be seen in Figure 1.b contain 6 layers, that are (1) 3,500$4,000 \mathrm{~mm} /$ year $213.03 \mathrm{~km}^{2}(12.09 \%)$, (2) 3,000-3,500 mm/year $332.48 \mathrm{~km}^{2}$ (18.86\%), (3) $2,500-3,000 \mathrm{~mm} /$ year $649.04 \mathrm{~km}^{2}(36.83 \%)$, (4) 2,000-2,500 mm/year $76.55 \mathrm{~km}^{2}(4.34 \%)$, (5) $1,500-2,00 \mathrm{~mm} /$ year $139.79 \mathrm{~km}^{2}(7.93 \%)$, and (6) < 1,500 mm/year $351.52 \mathrm{~km}^{2}(19.95 \%)$. 48 zone UTM coordinates tied all layers. Affine method which transformed satellite imagery screen shoot to UTM was used for coordinate transformation.

Thematic map of soil effective depth as can be seen in Figure 1.c contain 4 layers, that are (1) deep (> $90 \mathrm{~cm}) 493.91 \mathrm{~km}^{2}(28.02 \%)$, (2) medium depth $(60-90 \mathrm{~cm}) 430.16 \mathrm{~km}^{2}$ $(24.41 \%)$, (3) rather shallow $(30-60 \mathrm{~cm}) 227.10 \mathrm{~km}^{2}(12.89 \%)$, and $(4)$ shallow $(<30 \mathrm{~cm})$ $611.23 \mathrm{~km}^{2}(34.68 \%) .48$ zone UTM coordinates tied all layers. Affine method which transformed satellite imagery screen shoot to UTM was used for coordinate transformation.

Thematic map of flood as can be seen in Figure 1.d contain 2 layers, that are (1) non flood area $1,124.12 \mathrm{~km}^{2}(63.78 \%)$, (2) flood area $638.28 \mathrm{~km}^{2}(36.22 \%) .48$ zone UTM coordinates tied all layers. Affine method which transformed satellite imagery screen shoot to UTM was used for coordinate transformation. 


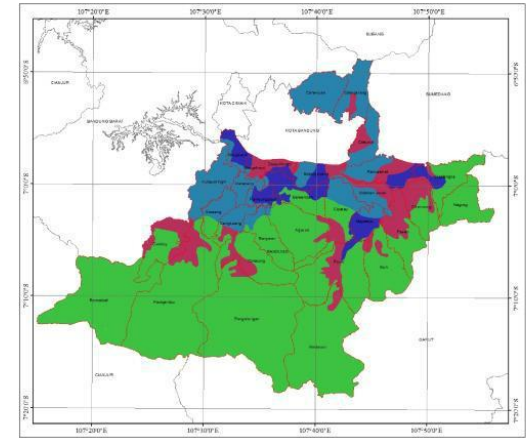

(a)

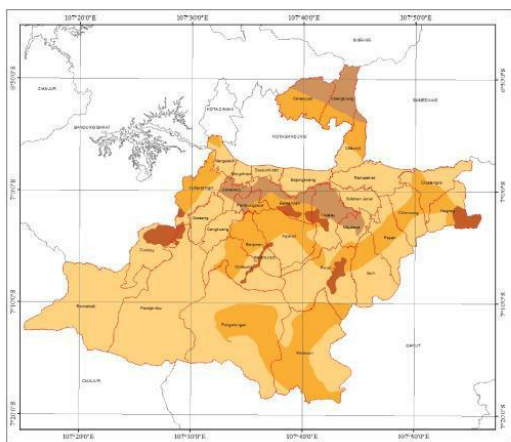

(c)
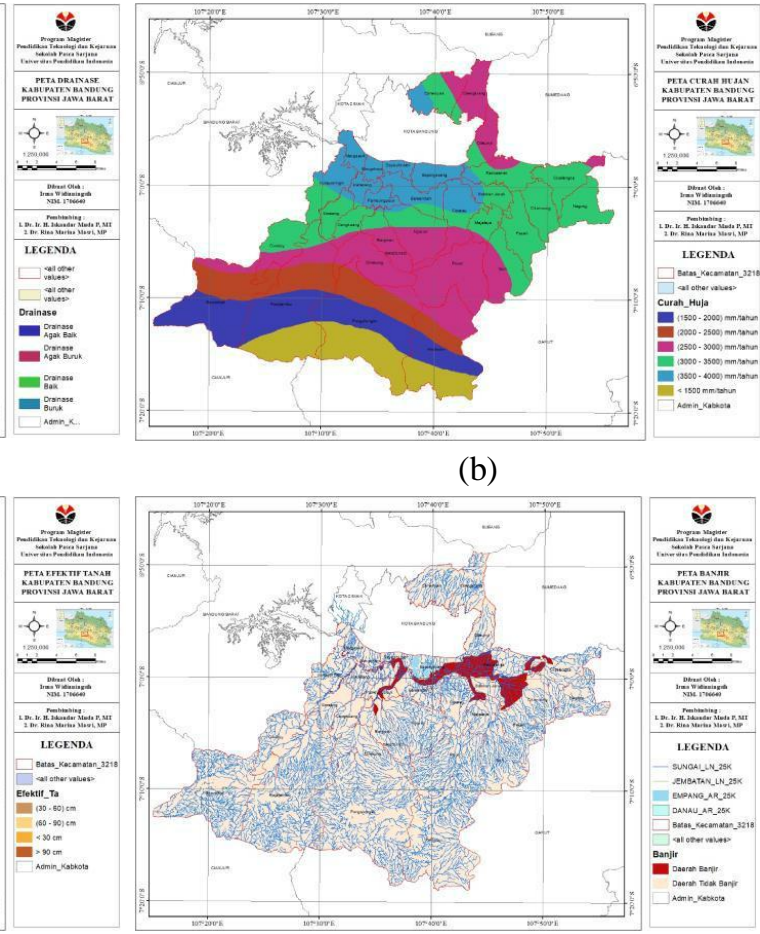

(d)

Fig. 1. Thematic Map of:a) Drainage, b) Rain Fall, c) Soil Effective Depth, and d) Flood.

Thematic map of soil textureas can be seen in Figure 2.a contain 3 layers, that are (1) smooth $52.57 \mathrm{~km}^{2}(2.98 \%)$, (2) medium $846.71 \mathrm{~km}^{2}(48.04 \%)$, and (3) rough $863.12 \mathrm{~km}^{2}$ $(48.97 \%) .48$ zone UTM coordinates tied all layers. Affine method which transformed satellite imagery screen shoot to UTM was used for coordinate transformation.

Thematic map of erosionas can be seen in Figure 2.b contain 4 layers, that are (1) no erosion $84.39 \mathrm{~km}^{2}(4.79 \%)$, (2) mild erosion $292.11 \mathrm{~km}^{2}(16.57 \%)$, (3) moderate erosion $1,202.68 \mathrm{~km}^{2}(68.24 \%)$, and (4) severe erosion $183.21 \mathrm{~km}^{2}(10.40 \%) .48$ zone UTM coordinates tied all layers. Affine method which transformed satellite imagery screen shoot to UTM was used for coordinate transformation.

Thematic map of rockas can be seen in Figure 2.c contain 4 layers, that are (1) a little rock $122.11 \mathrm{~km}^{2}(7 \%)$, (2) medium rock $268.36 \mathrm{~km}^{2}(15 \%)$, (3) a lot of rock $392.89 \mathrm{~km}^{2}(22$ $\%$ ), and (4) very much rock $979.04 \mathrm{~km}^{2}(56 \%) .48$ zone UTM coordinates tied all layers. Affine method which transformed satellite imagery screen shoot to UTM was used for coordinate transformation.

Thematic map of slopeas can be seen in Figure 2.d contain 6 layers, that are (1) flat $(0-3$ \%) $88.56 \mathrm{~km}^{2}(5.03 \%)$, (2) rather flat $(3-8 \%) 261.55 \mathrm{~km}^{2}(14.84 \%)$, (3) sloping $(8-15 \%)$ $4.74 \mathrm{~km}^{2}(0.27 \%)$, (4) rather steep $(15-25 \%) 685.68 \mathrm{~km}^{2}(38.91 \%)$, (5) steep $(25-40 \%)$ $100.11 \mathrm{~km}^{2}(5.68 \%)$, and (6) very steep (> $\left.40 \%\right) 621.76 \mathrm{~km}^{2}(35.28 \%) .48$ zone UTM coordinates tied all layers. Affine method which transformed satellite imagery screen shoot to UTM was used for coordinate transformation. 


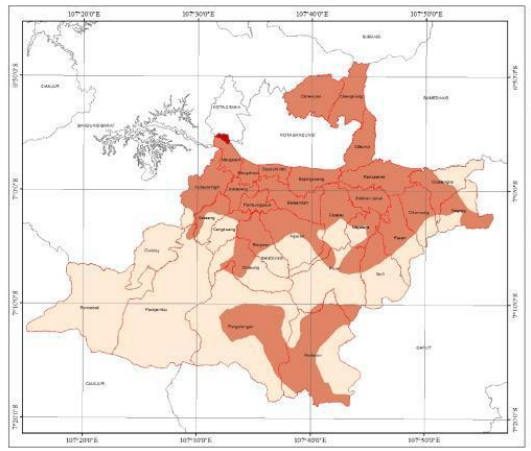

(a)

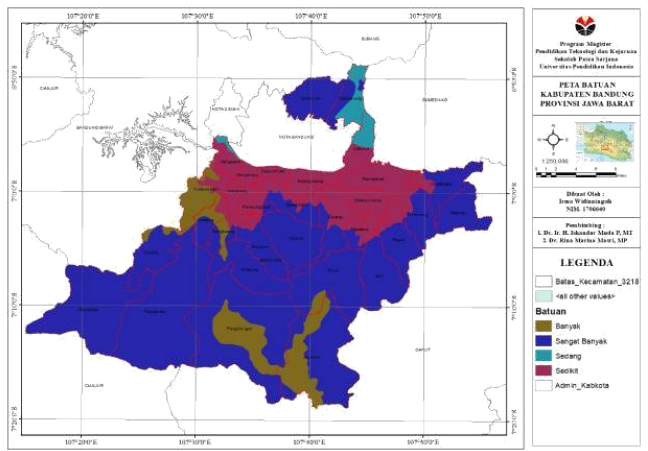

(c)

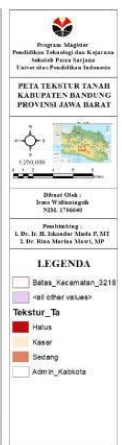

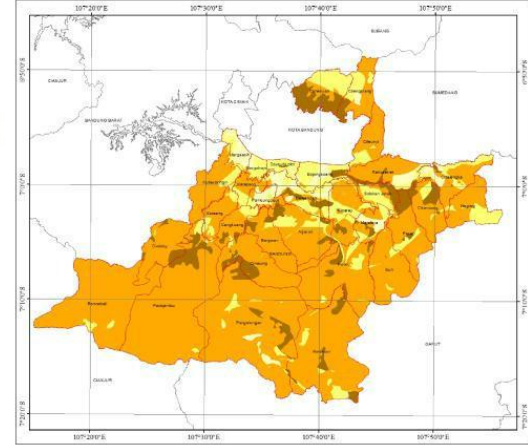

(b)

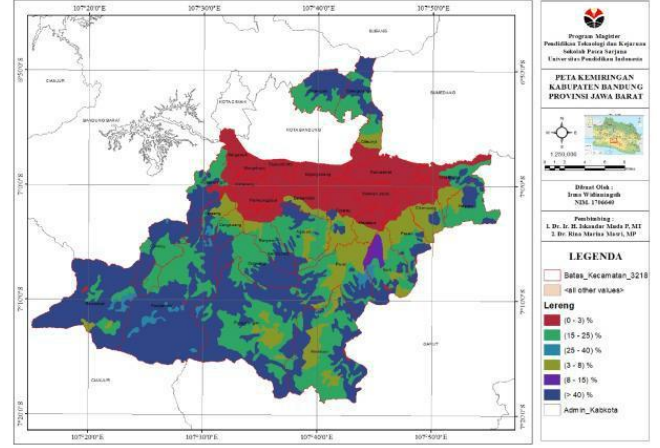

(d)

Fig. 2. Thematic Map of:a) Soil Texture, b) Erosion, c) Rock, and d) Slope.

\subsection{Map of Spatial Analysis Results for Vocational School Zone Based on GIS}

Map of spatial analysis results for vocational school zone based on GIS contain 12 layers as can be seen in Figure 3, that are (1) class of land capability I (40.83-43.55) $4.86 \mathrm{~km}^{2}(0.28$ $\%)$, (2) class of land capability II $(38.10-40.82) 82.16 \mathrm{~km}^{2}(4.66 \%)$, (3) class of land capability III (35.36-38.09) $138.66 \mathrm{~km}^{2}(7.87 \%)$, (4) class of land capability IV (32.63-35.35) $353.78 \mathrm{~km}^{2}(20.07 \%)$, (5) class of land capability V (29.90-32.62) $358.18 \mathrm{~km}^{2}(20.32 \%)$, (6) class of land capability VI (27.17-29.89) $469.12 \mathrm{~km}^{2}(26.62 \%)$, (7) class ofland capability VII (21.69-24.42) $19.59 \mathrm{~km}^{2}$ (1.11\%), (9) developer plan, (10) sub-district, (11) district vocational school, and (12) cultural heritage. 48 zone UTM coordinates tied all layers. Affine method which transformed satellite imagery screen shoot to UTM was used for coordinate transformation. 


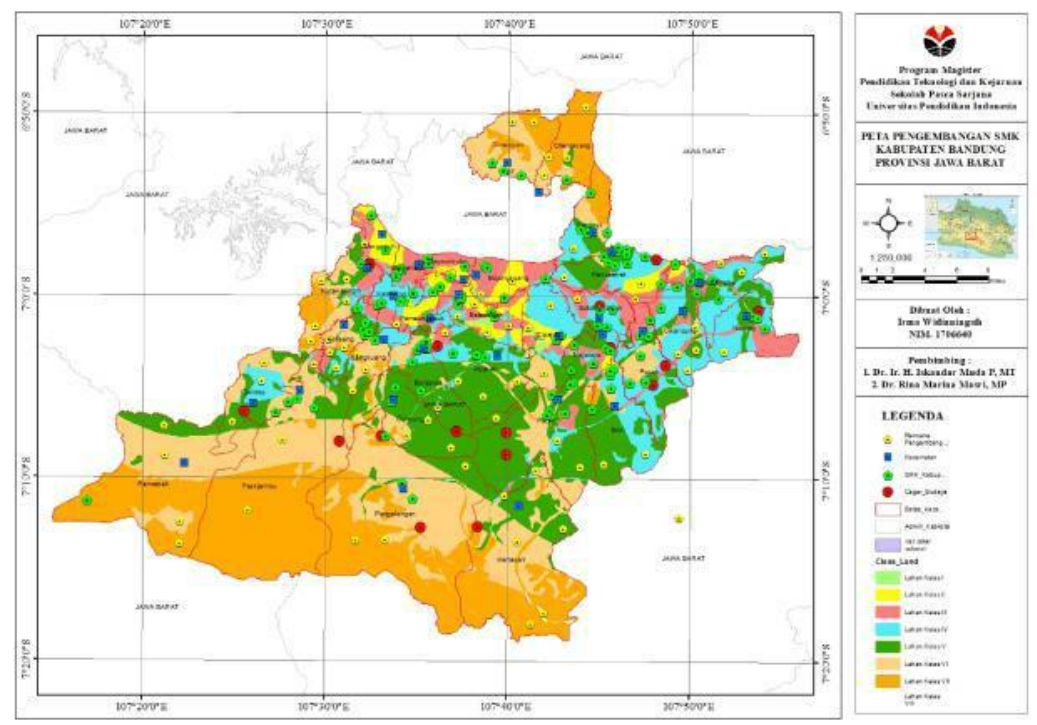

Fig. 3. Map of Spatial Analysis Results for Vocational School.

\section{Conclusion}

Existing environmental conditions that are used as input for multi-criteria evaluation in determining the zoning of vocational education areas based on Geographical Information System are drainage, rainfall, effective soil depth, flood, soil texture, erosion, rock and slope. Evaluation of environmental aspects is directed to determine the potential of land for the development of the vocational school in Bandung district. The condition of the environmental aspects which includes eight criteria is used as input to obtain the output of the land capability class map from the results of the digital spatial analysis process using ArcGIS 10.2.

The results of the spatial analysis of land capability using ArcGIS 10.2, Bandung district consists of 8 land capability classes which will be used as a space guide for zoning of vocational school areas. Class I of land capability is used usually for irrigated paddy fields and class VIII for protected forest area.

The main components determine the zone of vocational school area in terms of physical, social, economic and cultural components based on stakeholders (government, private and community) based on the Principal Component Analysis calculation results formed 4 factors that can represent 14 main components in determining the zone of the vocational school area. The factors that enter into component 1 are X10 (community characteristics), X11 (language differences), X12 (cultural heritage), X13 (religious diversity) and X14 (community development). Factors that correlate with component 2 are X4 (there is agricultural land), X5 (near agricultural land), X6 (there is plantation land) and X7 (near plantation land). Factors that correlate with component 3 are X3 (based on carrying capacity of the environment), X8 (there are regional potentials) and X9 (regional characteristics). Factors that correlate with component 4 are X1 (located in the city center) and X2 (located in the highlands). 
The results of the zoning analysis of the vocational school area which is a combination of evaluation of land capability with the main components of its stakeholders resulted in the development of 41 new vocational schools. The component that represents factor 1 with the highest value is X12 (cultural heritage). The component that represents factor 2 with the highest value is X6 (plantation land). The component that represents factor 3 with the highest value is X9 (regional characteristics). The component that represents factor 4 with the highest value is $\mathrm{X} 1$ (located in the city center).

Acknowledgments. The author is grateful to the Directorate of Higher Education, Rector of Universitas Pendidikan Indonesia, Dean of Faculty of Technology and Vocational Education, Head of Civil Engineering Education Department-Universitas Pendidikan Indonesia for allowing activities, validating research result and financial and moral support.

\section{References}

[1] Joerin, F.: Using GIS and outranking multicriteria analysis for land-use suitability assessment. International Journal of Geographical Information Science Taylor and Francis. pp. 153-174 (2001)

[2] Carver, S. J.:Integrating multi-criteria evaluation with geographical information system.International Journal of Geographical InformationSystems Taylor and Francis. pp. 321339(1991)

[3] Wahyudi, A., van Meirvenne, M., Cockx, L., and Mutaqin, D. M..: Geographic Information System and Decision Making for Multi Criteria Sanitary Landfill Allocation in Bandung Barat. Jurnal Perencanaan Wilayah dan Kota ITB. pp. 52-65(2009)

[4] Ismail, M. H.: Developing Policy for Suitable Harvest Zone using Multi Criteria Evaluation and GIS-Based Decision Support System. International Journal of Economic and Finance CCSE. pp. 105117 (2009)

[5] Yakar, F., Celik, F.: A Highway Alignment Determination Model Incorporating GIS and MultiCriteria Decision Making. Journal of Civil Engineering KSCE Springer. pp. 1847-1857 (2014)

[6] Bell, N., Schuurman, N., V. Hayes, M.: Using GIS-based methods of multicriteria analysis to construct socio-economic deprivation indices. International Journal of Health Geographics. pp. 1-19 (2007)

[7] Area, D., Kutoglu, H. S., Becek, K.: Landslide susceptibility mapping in an area of underground mining using the multicriteria decision analysis method. Environmental Monitoring Assessment Crossmark Springer. pp. 1-14 (2018)

[8] Gigovic, L., Drobnjak, S., Pamucar, D.: The Application of the Hybrid GIS Spatial Multi-Criteria Decision Analysis Best-Worst Methodology for Landslide Susceptibility Mapping. International Journal of Geoinformation MDPI. pp. 1-11 (2019)

[9] Masri, R. M., Purwaamijaya, I. M.: Spatial and Activities Models of Airport Based on GIS and Dynamic Model. Journal of Physics: Conference Series IOP Publishing. pp. 1-6 (2017)

[10] Masri, R. M., Purwaamijaya, I. M.: Multi Criteria Evaluation for Regional Function Based on Geographic Information System. 2017 3rd International Conference on Science inInformation Technology (ICSITech) IEEE. pp. 1-5 (2018)

[11] Purwaamijaya, I. M.: Multi criteria evaluation for universal soil loss equation based on geographic information system. Journal of Physics: Conference Series IOP Publishing. pp. 1-7 (2018) [12] Masri, R. M.: Environmental management and monitoring for education building development. Journal of Physics: Conference Series IOP Publishing. pp. 1-8 (2011) 